\title{
The Use of Patterns as an Urban Design Approach
}

\author{
Hernan Casakin 10
}

School of Architecture, Ariel University, P.O. Box 3, Ariel 44837, Israel, casakin@ariel.ac.il; Tel.: +972-508167756

Received: 16 September 2018; Accepted: 5 October 2018; Published: 9 October 2018

\begin{abstract}
Urban design is a complex problem-solving activity that commonly requires the aid of a variety of methods to support the process and enhance the quality of the outcomes. How to help designers with suitable methods to deal with ill-defined urban problems constitutes a major challenge in the urban design domain. In this regard, the use of urban design patterns is considered as a method that can contribute to urban design problem-solving. However, this tool was never investigated to understand its role in the task-related activities that take place during the design process by designers working in a team, and its influence on the creativity of the final design outcome as perceived by urban designers and students. Therefore, an empirical research based on a controlled experiment was carried out to explore the aid provided by design patterns during the conceptual stages of the process. Sixty-three master students working in teams of three were assigned a set of patterns to solve an urban design task. They were requested to use this material to produce as many creative conceptual solutions as possible. At the end of the sessions, they evaluated the creativity of their outcomes, and they completed a questionnaire about the aid afforded by the patterns. The solutions were also assessed by two independent urban designers. The study contributed to gain a better insight into the main design activities derived from the use of patterns as problem-solving tools and to unveil their contribution to urban design. The aid provided by the urban patterns was mainly concerned with task-related activities, and thereafter with team interactions. Overall, the use of patterns was seen to enhance the functionality of the design. Implications for design practice and design education are discussed.
\end{abstract}

Keywords: design patterns; urban design; problem-solving; creativity; urban design education; teamwork

\section{Introduction}

Design problems, and urban design problems, in particular, are ambiguous, lack clear initial conditions and completely specified goals and requirements, and demand the generation of innovative solutions $[1,2]$. For these reasons, urban design is a complex problem-solving activity that commonly requires a variety of methods such as heuristics, design principles, standards and guidelines to support the design activity. These approaches, however, have been criticized for being too simplistic, too specific, and hard to interpret [3]. Another important limitation is that they generally fail to deal with complex issues [4]. There are many reasons for this as complexity is bothersome for students and professional designers. Among these are the background and level of expertise of the design agents involved in the process, the broad and diverse body of knowledge necessary for an integrated design solution, and the difficulties to predict successful solutions based on a vast number of design variables that are hard to seize [5]. As a consequence, how to equip designers with adequate methods to tackle ill-defined urban problems has remained a major challenge both in professional practice and in education. In this regard, design patterns are considered a powerful resource containing comprehensive and easy to understand information, which can be applied to resolve conflicts between social and physical aspects of the design [6]. 
The present interest with patterns is related to Christopher Alexander, who authored "The timeless way of building" and "A pattern language". In these books, he introduced a theory and practical approach to architectural and urban design $[7,8]$. The notion of patterns was first introduced as an alternative approach for tackling ill-defined problems [9] in the architectural and urban fields [7]. The use of patterns as a kind of language was also found relevant in domains like software engineering, web design, and human-computer interaction, where they were acknowledged as a promising technique for assembling and reusing software architectures [10-13].

Patterns are concerned with problems related to specific design situations that explain how solutions can be efficiently applied. Basically, a pattern is composed of three parts which represent a relation between a context, a frequent design problem, and the fundamental nature of a solution to tackle the problem [8]. Moreover, pattern representations also inform how they are related to other relevant patterns, and present solution examples by means of visual and text information. According to Alexander [7], a suitable pattern language includes solutions containing recurring features and principles that are common in many feasible ways of solving the problem at hand.

Chung et al. [14] found that patterns differ from other approaches such as heuristics and guidelines in that they offer concrete solutions to specific problems, instead of abstract suggestions. Consequently, rather than replacing these methods, they can complement them. By providing design examples, patterns can be seen as more generative than reductive tools. Another advantage is that they aid in structuring problems, and creating functional and well-integrated design solutions [15]. While facilitating schemas to reinterpret a problem in terms of other smaller problems [7], patterns are considered as a prescriptive design approach that enables a fast generation of alternative design solutions. Some researchers consider that they enhance the chances for flexibility and adaptability to changing design conditions, leaving enough room for design creativity and innovation [16]. However, when used inadequately, they can also lead to fixation and the repetition of known solutions [17,18].

Urban design problem-solving is an increasingly complex activity demanding a thorough collaboration between members of a team [19]. Dealing with urban problems requires effective communication within teams with different goals, interests, and views of the problem. Consequently, the main challenge for design teams is how to generate mutual knowledge and integrate individual perspectives into shared ones $[20,21]$. Enhancing communication can contribute to this end with a positive effect on both the design process and the outcome [22]. In this vein, using design patterns can be instrumental in keeping a fluent communication and exchange of information about recurrent design situations. This tool can enhance the interaction and shared understanding among team members and can assist in the efficient coordination of design activities [3]. The information contained in the patterns can provide critical guidance to urban designers on how to make appropriate decisions about the design task at different levels of scale and detail [23,24].

The design studio is at the core of most urban design curricula and it is the place where students learn to think as a designer while dealing with design problem-solving tasks. In addition to problem solving and communication, an important emphasis in the studio is set on design creativity and innovation [25]. During the design studio sessions, students are supposed to reflect upon the creativity of their designs [26] while they develop their thinking and learning skills [27]. The production of creative outcomes is concerned with an exploratory activity demanding non-routine and original thinking. However, to consider a design as creative, originality is not enough, and some kind of value is necessary [28]. In addition to originality, the usability and aesthetic values of a product are also important. These are the three basic properties of any creative design [29-31]. However, producing creative designs is an intricate activity that entails taking risks to challenge unfamiliar, complex, and ill-structured situations [32]. Unfortunately, most traditional studios are governed by a hidden curriculum that allows them to regulate the quality of the design outcomes [33]. Instead of advancing agendas in support of the development of creativity, they prefer to avoid unwanted hazards and to strengthen the status quo urban theory. Under these circumstances, how to help students defy 
traditional and more conservative educational systems and equip them with efficient tools to support design creativity has remained an open question.

As an educational method in the studio, design patterns have the potential to enrich traditional teaching systems, such as the Ecole de Beaux Arts. This approach, which continues to be largely influential in many schools of architecture and urbanism, stresses individual knowledge transfer from tutors to students $[34,35]$. Patterns can help to simplify the complexity of urban problems, as requested in the design studio. By facilitating criteria for valuing experiences, ideas, personal views, these instruments aid students to develop and consolidate their knowledge and creative skills gradually [36], while they gain independence from their design studio tutors [37,38]. Griffiths and Pemberton [39] proposed ways to use pattern language in design education, such as connecting patterns with design theory, using existing patterns in practical exercises, and exploring and identifying new patterns. Practicing with patterns in the design studio helped to enhance design team interactions and improve the creativity of the outcomes. Some researches stressed the importance of empirically studying the use of patterns in both design practice and design education $[3,40]$. However, works on design patterns are mostly historical or anecdotal, and empirical studies are scarce. To the best of our knowledge, this tool was never explored in the context of task-related activities carried out by urban designers working in a team. Therefore, an empirical investigation was carried out to study how urban design patterns can assist design teams during the conceptual stages of the design process, and how these affect the final design outcome as perceived by professionals and students. One general objective was to test whether students and urban designers have similar conceptions of the creativity of the designs produced with the aid of patterns. A second objective was to explore how the use of design patterns helped students to deal with the task and exchange information with the other team members during the process. Another objective was to identify what the main factors characterizing the design activity are, and how they contribute to the creativity of the design outcomes, mainly with regard to the originality, functionality, aesthetic value, and the overall value of the design solutions. Implications for practice and design education were also considered.

In spite of the limitations of carrying out the research in a lab environment conditions, and the relatively small study sample, the study contributes to gaining a further understanding into the use of patterns in support of the urban design activities developed during the conceptual stages of the design process. It also fostered the present state of knowledge about the potential use of this approach in the urban design studio as a complement to other traditional education models.

\section{Materials and Methods}

\subsection{Research Goals}

An investigation was accomplished to explore how using design patterns can contribute to urban design problem-solving activities during the conceptual stages of the process. A focus was on the task, the team, and the creativity of the design outcomes. One general objective was to analyze whether urban designers and urban design students have a similar perception of creativity, and how alike these are. Thus, the first goal of the study was to examine how urban designers assess the creativity of design students by analyzing the originality, functionality, aesthetic value, and the overall value of their products. The second goal was to learn how students assess the creativity of their own urban design products by considering variables similar to those used by urban designers. In addition, we wanted to understand how employing design patterns help students to deal with the task and interact with the other team members during the process. The third goal was to identify the main design factors and determine their contribution to the creativity of the urban design outcome. We validated this procedure by analyzing the relationships between these factors, and the assessment of design creativity by both urban designers and students. We assume that the nearer the urban designers are to the evaluations of creativity in the urban designs of students, the higher the prospects that the lessons learned in educational environments such as the urban design studio will be assimilated by the students. 


\subsection{Participants and Set $U p$}

Sixty-three master students (38 females and 25 males) from the Faculty of Architecture and Urbanism, the Department of Urbanism at TU Delft were recruited for the design study. Students were recruited in the urban studio and invited to participate in the experimental sessions. They worked in teams composed of three members and, in return for their participation, they received a symbolic payment. Design patterns were used as a design method, and the students were asked to tackle an urban design problem.

\subsection{Design Session}

Students were assigned a task sheet that included general instructions, photographs and a map of the area, and a design problem. They were also assigned a collection of four patterns, which they used to solve the task (see Figure 1). In addition, participants were provided with several A3 sheets of paper and used them to generate as many creative urban design solutions as they could.

\section{Borders of public squares}

"When squares have their borders and internal areas poorly defined they look unclear; they are difficult to identify and understand."

Make the borders of a public square clear and legible. Define the main places and spaces in a square in such a way that they will be easily recognizable and provide them with a strong identity.

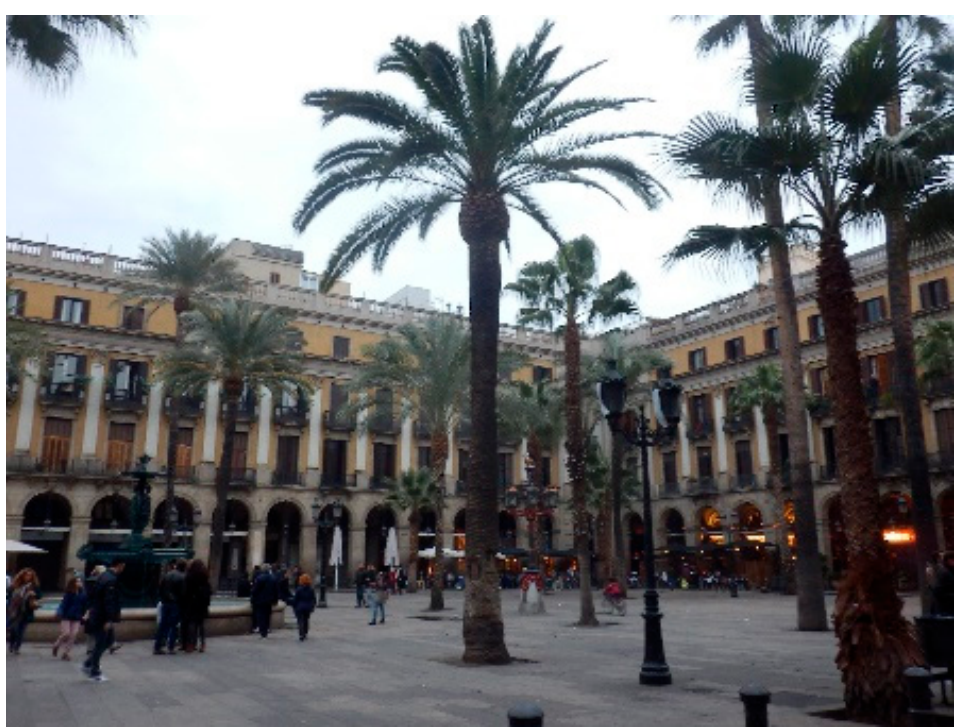

(a)

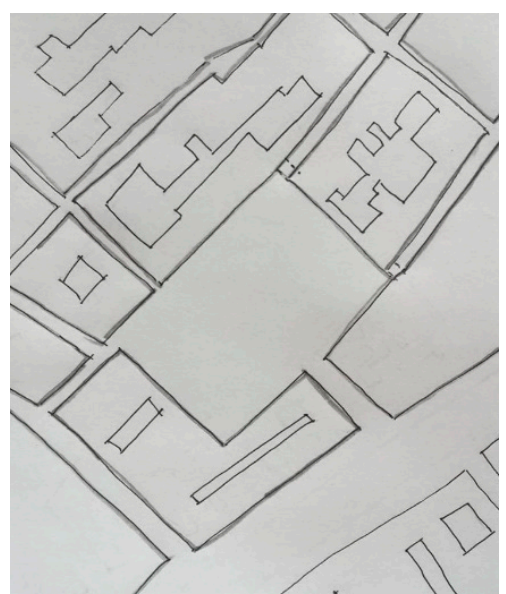

(b)

Figure 1. Example of a design pattern provided to the students when dealing with the design task. (a)

Perspective view. (b) Plan view Photography by Author.

\subsection{Judges}

The design outcomes obtained from the design sessions (sketches on the sheets administered to the participants) were scored independently by two naive judges, both experienced urban designers who volunteered their time. They were given a set of randomly ordered photocopies of the students' sketches, which were coded to protect the subjects' identity.

\subsection{Design Task, Procedure, and Instruments}

Participants were requested to design a public space for the sake of revitalizing an awkward area situated at the front of Amsterdam Schiphol Airport. To this end, students were encouraged to come up with design ideas about spaces and activities that could convert the access to the airport a pleasant and welcoming experience. For example, the brief called for the design of small human scale urban places 
with clear limits and at various levels of privacy, in addition to distinguishable circulation paths for the connection of the different areas allocated in the public space (see Appendix A). Due to the nature of the study, the design should be developed at a conceptual level. Participants were familiarized with the area, including socio-cultural, and physical issues of the task. Each session lasted half an hour, where $10 \mathrm{~min}$ were given to develop a final solution and a concise description of it. About 15 min were added when the sessions ended for the completion of questionnaires concerned with the task and the design outcome, and another 15 additional minutes were devoted to a debriefing activity.

Building on the categorization system suggested by Badke-Schaub et al. [22] and Casakin \& Badke-Schaub [21], an individual questionnaire was delivered to the participants that represented their viewpoints and assessments about the aid provided by the patterns to the design. It included 12 items such as "The design patterns helped me to think about new ideas", "The design patterns helped me to make clarifications about the problem, "The design patterns helped me to understand what other team members are saying about the problem", or "The design patterns helped me to provide assistance to others" (see Table 1). Cronbach's alpha, which is a measure of reliability reflecting how closely related a set of items are as a group, was used to assess the internal consistency of the questionnaire. Thus, the closer the items are related, the higher the Cronbach's alpha will be [41]. The resulting Cronbach's alpha coefficient for the present questionnaire was 0.75 , which is considered an acceptable value. In addition, students and urban designers were asked to evaluate the creativity of the final outcome with regard to originality, functionality, aesthetic value, and overall value (see Tables 2 and 3). These items were validated in prior studies $[42,43]$. All participants responded using a scale of five points, where $1=$ "Not at all", and $5=$ "Quite a lot".

Cohen's kappa coefficient was run to determine if there was an agreement between the two urban designers' judgment on the creativity of the final solution. Cohen's kappa coefficient $(\kappa)$ is an index or statistic that measures inter-rater agreement when observing or coding qualitative (categorical) variables. It is considered to be an improvement over using a percent agreement calculation since $\kappa$ takes into account the probability of the agreement occurring by chance. A kappa coefficient of 1 means a perfect agreement, while a kappa of 0 implies an agreement equivalent to chance [44]. In the present study, there was a substantial agreement for all the assessed variables: originality, $\mathrm{k}=0.760$, $p<0.001$; functionality, $\mathrm{k}=0.737, p<0.001$; aesthetic value, $\mathrm{k}=0.752, p<0.001$; and overall value, $\mathrm{K}=$ $0.775, p<0.001$.

Table 1. The means and standard deviations of the aid provided by the design patterns, assessed by the students ${ }^{\mathrm{a}}$.

\begin{tabular}{ccc}
\hline Variable of Assessment Used by the Students & Mean & Standard Deviation \\
\hline Definition of problems & 3.86 & 0.877 \\
Analysis of ideas & 3.79 & 0.953 \\
Clarifications of ideas & 3.73 & 0.919 \\
Evaluation of ideas & 3.59 & 1.116 \\
Take final design decisions & 3.48 & 0.895 \\
Stating new ideas & 3.06 & 0.896 \\
Produce an innovative solution & 2.75 & 0.842 \\
Support ideas from others & 3.90 & 0.756 \\
Understanding what others are saying about the problem & 3.94 & 0.914 \\
Positive atmosphere & 3.86 & 1.014 \\
What the team has been doing so far & 2.81 & 1.162 \\
Assistance to others & 3.40 & 0.976 \\
\hline
\end{tabular}

a The 5-value scales ranged from low ratings (=1) to high ratings (=5), each level of rating being described verbally. 
Table 2. The means and standard deviations of the creativity variables assessed by the students ${ }^{\text {a }}$.

\begin{tabular}{ccc}
\hline Variable of Assessment by Students & Mean & Standard Deviation \\
\hline Originality & 2.95 & 0.771 \\
Functionality & 3.97 & 0.718 \\
Aesthetic value & 3.32 & 0.947 \\
Overall value & 3.40 & 0.661 \\
\hline
\end{tabular}

a The 5-value scales ranged from low ratings (=1) to high ratings (=5), each level of rating being described verbally.

Table 3. The means and standard deviations of the creativity variables assessed by the urban designers.

\begin{tabular}{ccc}
\hline Variable of Assessment by Urban Designers & Mean & Standard Deviation \\
\hline Originality & 2.55 & 0.974 \\
Functionality & 2.87 & 0.583 \\
Aesthetic value & 2.39 & 0.891 \\
Overall value & 2.59 & 0.599
\end{tabular}

a The 5-value scales ranged from low ratings (=1) to high ratings (=5), each level of rating being described verbally.

\section{Results}

In the first stage of the data analysis, a factor analysis was carried out for the assessments made by the students on the aid provided by urban patterns during the process. Factor analysis is a statistical method that measures the impact of a few un-observed variables, known as factors, on many observed variables. Essentially, this technique is used to reduce a large number of variables into a smaller dataset that is more manageable and easier to understand [45].

In the second stage of data analysis, the association between the factors emerging from the factor analysis and the assessments of the design outcome regarding originality, functionality, aesthetic value, and overall value were analyzed using regressions. Regression analysis enables to explore the relationship between two or more variables. This statistical tool enables to forecast change in a dependent variable (salary, for example) depending on the given amount of change in one or more independent variables (gender and professional background, for example) [46]. In this study, regressions were carried out as follows: (i) regression of the factors of the use of urban patterns based on the students' responses and the evaluation of the final outcome by the urban designers; (ii) regression of the factors of the use of urban patterns based on the students' responses, and their own evaluation of the final outcome. The creativity of the final solution was independently rated by both architects and students.

\subsection{Factor Analysis of Students' Evaluations}

The 12 variables evaluated by the students were factor analyzed (see Table 4). Four valid factors emerged from this procedure, as showed by their values $(>1.00)$ and the percentages of the variance for which they account $(>65.81 \%$ ). The first and strongest factor (accounting for $30.08 \%$ of the variance) mainly represents the attention to the context and constraints of the design task, and may, therefore, be labeled as 'analysis and assessment of the design'. The second factor accounting for $16.04 \%$ of the variance represents attention to the novelty of ideas and solutions. Thus, the factor should be labeled as 'design innovation'. The third factor accounting for $10.70 \%$ of the variance is highly saturated on 'understand what others say about the design', 'approval of and support of other team members', and 'keep a positive atmosphere'. Therefore, the factor may be labeled as 'team cohesion'. Finally, the fourth and less dominant factor is saturated on 'what the team has been doing so far' and 'assistance provided to others', and hence the factor may be labeled as 'design reflection'.

\subsection{Regression Analyses of the Design Factors on Urban Design Creativity}

In order to examine the relation of the design factors to the different aspects of the creativity of the urban design outcome, we performed different regression analyses with the factors as predictors and the evaluation of the creativity components as dependent variables. 
Table 4. The results of a factor analysis on the variables assessed by the students ${ }^{\mathrm{a}}$.

\begin{tabular}{|c|c|c|c|c|}
\hline Variables & $\begin{array}{c}\text { Factor } 1 \text { Analysis } \\
\text { and Assessment } \\
\text { of the Design }\end{array}$ & $\begin{array}{c}\text { Factor } 2 \\
\text { Design } \\
\text { Innovation }\end{array}$ & $\begin{array}{c}\text { Factor } 3 \\
\text { Team } \\
\text { Cohesion }\end{array}$ & $\begin{array}{c}\text { Factor } 4 \\
\text { Design } \\
\text { Reflection }\end{array}$ \\
\hline Evaluation of ideas & 0.839 & -0.058 & 0.056 & -0.132 \\
\hline Definition of problems & 0.746 & 0.041 & 0.063 & 0.191 \\
\hline Analysis of ideas & 0.691 & 0.412 & 0.059 & -0.003 \\
\hline Take final design decisions & 0.672 & 0.393 & 0.075 & -0.057 \\
\hline Clarifications of ideas & 0.617 & 0.367 & 0.060 & 0.436 \\
\hline Stating new ideas & 0.174 & 0.781 & 0.047 & 0.170 \\
\hline Producing an innovative solution & 0.192 & 0.760 & -0.104 & 0.028 \\
\hline Understand what others say about the design & -0.017 & 0.175 & 0.834 & 0.168 \\
\hline Approval of and support of other team members & 0.066 & -0.267 & 0.696 & -0.008 \\
\hline Keep a positive atmosphere & 0.248 & 0.258 & 0.585 & -0.418 \\
\hline What the team has been doing so far & 0.032 & 0.242 & 0.021 & 0.746 \\
\hline Assistance provided to other members & 0.129 & -0.347 & 0.537 & 0.546 \\
\hline Eigenvalue of factor & 3.610 & 1.924 & 1.283 & 1.080 \\
\hline Percentage of variance accounted for by factor & 30.08 & 16.04 & 10.70 & 9.00 \\
\hline
\end{tabular}

Note. The numbers in the cells are saturations of the variables on each of the factors. The highest saturations that are considered for defining the factor are typed in bold. ${ }^{a}$ The factor analysis was performed according to the principal components of the rotated varimax procedure after Kaiser normalization. It should be said that factor rotation is the mathematical procedure for interpreting factor matrixes. For any solution with two or more factors, there exist an infinite number of orientations of the factors that will explain the data similarly well. Although there is no single solution, a solution must be chosen from the infinite possibilities. Thus, the purpose of factor rotation is to rotate the factors in a multidimensional space to arrive at a solution with the best simple structure. Varimax is recognized as the best orthogonal rotation procedure and it is most often used in social and psychological research. For further literature on this procedure, and the exploratory factor analysis in general, please see Fabrigar et al. [47].

\subsubsection{Regression Analysis of the Design Factors of Students on the Originality Evaluation by Students}

The first regression corresponds to the students' factors on their assessment of the originality of the final solution. The overall results of the four factors are highly significant and indicate that only one factor (Factor 2; concerned with the novelty of ideas and solutions) was related to originality. The fourth factor dealing with reflection was only close to significance (see Table 5).

Table 5. The regression analysis of the factors on the originality evaluation by students.

\begin{tabular}{cccccc}
\hline & Sum of Squares & Df & Mean Squares & F & Sig. \\
\hline Regression & 8.760 & 4 & 2.190 & 4.521 & $0.003^{\mathrm{a}}$ \\
Residual & 28.097 & 58 & 0.484 & & \\
Total & 36.857 & 62 & & & \\
\hline
\end{tabular}

a R Square 0.238 Standardized Beta Coefficients; First factor $0.055 \mathrm{t}=0.476 \mathrm{~ns}$; Second factor $0.427 \mathrm{t}=3.724(p<0.001)$;

Third factor $0.094 \mathrm{t}=0.823 \mathrm{~ns}$; Fourth factor $0.088 \mathrm{t}=1.819 \mathrm{~ns}$.

3.2.2. Regression Analysis of the Design Factors by Students on the Functionality Evaluation by Students

The second regression corresponds to the students' factors on their evaluation of the functionality of the final design outcome. The overall results of the four factors are significant, and indicate that only factor 1 (analysis and assessment of design) was associated with functionality (see Table 6).

Table 6. The regression analysis of the factors on the functionality evaluation by students.

\begin{tabular}{cccccc}
\hline & Sum of Squares & Df & Mean Squares & F & Sig. \\
\hline Regression & 4.798 & 4 & 1.199 & 2.563 & $0.048^{\mathrm{a}}$ \\
Residual & 27.139 & 58 & 0.468 & & \\
Total & 31.937 & 62 & & &
\end{tabular}

\footnotetext{
a R Square 0.150 Standardized Beta Coefficients; First factor $0.219 \mathrm{t}=2.518(p<0.01)$; Second factor $0.066 \mathrm{t}=762 \mathrm{~ns}$;
} Third factor $0.158 \mathrm{t}=1.818 \mathrm{~ns}$; Fourth factor $-0.015 \mathrm{t}=-0.172 \mathrm{~ns}$. 
3.2.3. Regression Analysis of the Design Factors by Students on the Aesthetic Value Evaluation by Students

The third regression is of the students' factors on their evaluation of the aesthetic value of the final design. The overall results are close to significance and indicate that only factor 3 (team cohesion) was related significantly (see Table 7).

Table 7. The regression analysis of the factors on the aesthetic value evaluation by students

\begin{tabular}{cccccc}
\hline & Sum of Squares & Df & Mean Squares & F & Sig. \\
\hline Regression & 7.801 & 4 & 1.950 & 2.364 & $0.063^{\mathrm{a}}$ \\
Residual & 47.850 & 58 & 0.825 & & \\
Total & 55.651 & 62 & & & \\
\hline
\end{tabular}

a R Square 0.140 Standardized Beta Coefficients; First factor $0.101 \mathrm{t}=0.878 \mathrm{~ns}$; Second factor $0.129 \mathrm{t}=1.116 \mathrm{~ns}$; Third factor $0.294 \mathrm{t}=2.552(p<0.05)$; Fourth factor $0.111 \mathrm{t}=-0.961 \mathrm{~ns}$.

3.2.4. Regression Analysis of the Design Factors by Students on the Overall Value Evaluation by Students

The last regression of the students' factors on their self-assessment is on the overall value of the final product. The overall results are highly significant and demonstrate that only one factor was related to originality, and this is factor 3: team cohesion (see Table 8).

Table 8. The regression analysis of the factors on the overall value evaluation by students.

\begin{tabular}{cccccc}
\hline & Sum of Squares & Df & Mean Squares & F & Sig. \\
\hline Regression & 5.589 & 4 & 1.397 & 3.771 & $0.009^{\mathrm{a}}$ \\
Residual & 21.490 & 58 & 0.371 & & \\
Total & 27.079 & 62 & & & \\
\hline
\end{tabular}

a R Square 0.206 Standardized Beta Coefficients; First factor $0.122 \mathrm{t}=0.185 \mathrm{~ns}$; Second factor $0.129 \mathrm{t}=1.666 \mathrm{~ns}$; Third factor $0.241 \mathrm{t}=3.119(p<0.01)$; Fourth factor $0.033 \mathrm{t}=-0.279 \mathrm{~ns}$.

\subsubsection{Regression Analysis of the Design Factors on the Originality Evaluation by Urban Designers}

The fifth regression corresponds to the students' factors on the assessment of the urban designers on the originality of the final solution. The overall results are highly significant and indicate that only factor 1 (analysis and assessment of design) was related to originality (see Table 9).

Table 9. The regression analysis of the factors on the originality evaluation by urban designers.

\begin{tabular}{cccccc}
\hline & Sum of Squares & Df & Mean Squares & F & Sig. \\
\hline Regression & 10.743 & 4 & 2.686 & 3.283 & $0.018^{\mathrm{a}}$ \\
Residual & 48.114 & 58 & 0.830 & & \\
Total & 58.857 & 62 & & &
\end{tabular}

a R Square 0.183 Standardized Beta Coefficients; First factor $-0.384 \mathrm{t}=-3.2331(p<0.01)$; Second factor 0.072 $\mathrm{t}=0.609 \mathrm{~ns}$; Third factor $0.165 \mathrm{t}=1.388 \mathrm{~ns}$; Fourth factor $0.053 \mathrm{t}=-0.446 \mathrm{~ns}$.

\subsubsection{Regression Analysis of the Design Factors on the Functionality Evaluation by Urban Designers}

The sixth regression is of the students' factors on the assessment of the urban designers on the functionality of the design. The overall results are highly significant and demonstrate that two of the four factors were related to functionality, and these are factor 1 (analysis and assessment of design) and factor 3 (team cohesion; see Table 10). 
Table 10. The regression analysis of the factors on the functionality evaluation by urban designers.

\begin{tabular}{cccccc}
\hline & Sum of Squares & Df & Mean Squares & F & Sig. \\
\hline Regression & 3.293 & 4 & 0.823 & 2.681 & $0.040^{\mathrm{a}}$ \\
Residual & 17.810 & 58 & 0.307 & & \\
Total & 21.103 & 62 & & & \\
\hline
\end{tabular}

a R Square 0.156 Standardized Beta Coefficients; First factor $-2.36 \mathrm{t}=-1.957 \mathrm{~ns}$; Second factor $0.155 \mathrm{t}=1.287 \mathrm{~ns}$; Third factor $0.274 \mathrm{t}=2.268(p<0.05)$; Fourth factor $0.037 \mathrm{t}=-0.310 \mathrm{~ns}$.

3.2.7. Regression Analysis of the Design Factors on the Aesthetic Value Evaluation by Urban Designers

The next regression is of the students' factors on the assessment of the urban designers on the aesthetic value of the final outcome. The overall results are significant and indicate that only factor 1 (analysis and assessment of design) was associated with aesthetic value (see Table 11).

Table 11. The regression analysis of the factors on the aesthetic value evaluation by urban designers.

\begin{tabular}{cccccc}
\hline & Sum of Squares & Df & Mean Squares & F & Sig. \\
\hline Regression & 5.266 & 4 & 1.316 & 1.737 & $0.154^{\mathrm{a}}$ \\
Residual & 43.957 & 58 & 0.758 & & \\
Total & 49.222 & 62 & & & \\
\hline
\end{tabular}

a R Square 0.107 Standardized Beta Coefficients; First factor $-0.270 t=-2.179(p<0.05)$; Second factor 0.086 $\mathrm{t}=0.691 \mathrm{~ns}$; Third factor $0.161 \mathrm{t}=1.298 \mathrm{~ns}$; Fourth factor $0.024 \mathrm{t}=-0.848 \mathrm{~ns}$.

\subsubsection{Regression Analysis of the Design Factors on the Overall Value Evaluation by Urban Designers}

The last regression corresponds to the students' factors on the assessment of the urban designers on the overall value of the final product. The overall results for the four factors are highly significant and indicate that only factor 1 (analysis and assessment of design) was related to the overall value (see Table 12).

Table 12. The regression analysis of the factors on the overall value evaluation by urban designers.

\begin{tabular}{cccccc}
\hline & Sum of Squares & Df & Mean Squares & F & Sig. \\
\hline Regression & 3.975 & 4 & 0.994 & 3.150 & $0.021^{\mathrm{a}}$ \\
Residual & 18.295 & 58 & 0.315 & & \\
Total & 22.270 & 62 & & & \\
\hline
\end{tabular}

a $R$ Square 0.178 Standardized Beta Coefficients; First factor $-0.321 \mathrm{t}=-2.694(p<0.01)$; Second factor 0.229 $\mathrm{t}=1.925 \mathrm{~ns}(p=0.059)$; Third factor $0.152 \mathrm{t}=1.275 \mathrm{~ns}$; Fourth factor $-0.015 \mathrm{t}=-0.122 \mathrm{~ns}$.

\section{Discussion}

This study dealt with the use of patterns as urban design aids. It centered on the analysis of correspondences and divergences between urban designers and design students in the assessment of the creativity of design outcomes. Four significant variables defining design creativity were considered and included: originality, functionality, aesthetic value, and overall value $[42,43]$. The high degree of correspondence between the two judges that assessed the final outcomes confirms that the expert judgment of design creativity is a reliable and genuine method of assessment.

The results were obtained from a factor analysis carried out with the twelve variables analyzed by the students on the use of urban patterns. It was found that the four factors consisted of 'analysis and assessment of the design', 'design innovation', 'team cohesion', and 'design reflection. The most dominant factor is 'analysis and assessment of the design' representing variables such as 'clarifications of ideas', 'analysis of ideas', 'evaluation of ideas', and 'definitions of problems'. These results may indicate that when students are asked to assess the use of design patterns, their focus is mainly set on the analysis and evaluation of the design, including both problem and design ideas [48]. On 
the other hand, the aid of the design patterns in the synthesis design activity-concerned with the development of design solutions-was evident in the second dominant factor represented by 'design innovation', which included the variables of 'stating new ideas' and 'producing innovative solutions'. The study by Stempfle and Badke-Schaub [49] suggests that in the usual thinking process of design teams, the generation of the solution ideas is followed by evaluations, except when there are questions or clarifications. If an evaluation yields a positive result, then the solution is normally accepted. Otherwise, new solution ideas are pursued. It is remarkable that overall, the use of design patterns was perceived by the students as an instrument for analysis and evaluation, rather than as a means for supporting the generation of novel design solutions. This result is in line with previous studies arguing that patterns are effective in structuring problems [15], and those that raised questions regarding their contribution to design creativity and innovation [16]. Another interesting result is that whereas the most dominant factors centered on the design task, the less important ones focused on the team activities.

The results from the regression coefficients between the four factors emerging from the factor analysis and the assessment by the students of the design outcome indicated that the assessment of the originality of the urban design corresponds mainly to the 'novelty of ideas and solutions'. It is not surprising that when students are requested to assess design originality their attention is directed towards innovation. However, different results were found from the regression coefficients between the four factors resulting from the students' factor analysis and the assessment of the originality of the design by the urban designers. According to their view, 'analysis and evaluation of the design' was the dominant factor but with a negative contribution to the originality of the design. As commented before, it is possible that students used the urban patterns more as an analytical tool to structure, inspect and judge their ideas and outcomes, than as a means to generate innovative ideas. In this sense, employing patterns for analysis and evaluation operations characterizes the design as a convergent activity [50]. As a result of this, the generation of novel solutions (characteristic in divergent design activities) was to a certain extent limited. This claim is supported by the findings of the factor analysis presented above, where the 'analysis and evaluation of the design' was more dominant than the generation of new design outcomes.

Findings from the regression equation of the factors that predicted the evaluation of the functionality of the design by the students corresponded to the 'analysis and evaluation of the design'. Whereas the assistance provided by the patterns was largely on the assessment of the design task, this dominant factor had a positive impact in enhancing the functionality of the design. Nevertheless, different results were observed from the regression coefficients between the four factors and the evaluation carried out by the urban designers on the functionality of the design. In their view, 'team cohesion' had a positive contribution to the design use. One of the biggest challenges that design teams must face is to ensure that members exchange information and interact in a manner that they promote cohesion and collaboration [51,52]. Thus, it is suggested that the higher the cohesion and knowledge integration among team members, the better the contribution of the design patterns to the functionality of the urban design outcomes [19,22].

Findings from the regression equation of the factors analyses that predicted the evaluation by the students on the aesthetic value of the outcome corresponded also to the 'team cohesion'. Judgments of aesthetic value, also called judgment of sentiment and taste [53], hinges on the capability to discriminate at a sensory-emotional and intellectual level [54]. Scholars refer to aesthetic assessment as the "critical reflection on art, culture and nature' [55]. In design, aesthetic judgment is concerned with the sensory and affective appreciation of an object. Aesthetic assessment is subjective and personal, and in many cases is a matter of taste. Therefore, arriving at a common understanding on how a beautiful object should look like demands from the team to realize how the other members appreciate and criticize the design. It seems that for this to happen, some level of team cohesion must be attained. On the other hand, results from the regression analysis between the four factors and the evaluation by the urban designers indicated that the aesthetic value of the urban design corresponded to the 'analysis and evaluation of the design'. However, this variable had a negative contribution, suggesting that 
when used for convergence activities [50], design patterns may be detrimental to the development of aesthetic solutions.

The regression analyses that followed the factor analysis and the assessment by the students of the overall value of the design corresponded to 'team cohesion'. It is apparent that gaining a common understanding of the design contributed to align the views of the team members about the value of the final design solution [51]. Nevertheless, the assessment carried out by the urban designers indicated that the overall value of the design solution mainly corresponded to the 'analysis and evaluation of the design'. Once again, this variable was found to have a negative contribution, suggesting that the aid provided by design patterns as an assessment tool was counterproductive for the general value of the final solution.

\section{Conclusions}

This study contributed to gain a further understanding of the use of design patterns as an approach in urban design problem-solving activities during the conceptual stages of the process. Empirical evidence was provided for the first time to figure out the role of this tool in task-related activities that occur during the design process by designers working in a team, and its effect on the creativity of the final design outcome.

It was possible to understand how the availability of concrete solutions helped to deal with the task, interact with other team members, and arrive at a final solution. Moreover, a focus was set on how urban designers compared to students assess the final design solutions.

From the perspective of the students, the aid provided by the urban patterns was mainly concerned with the task, and thereafter with the interaction of the team. Overall, this tool assisted in the analysis and assessment of the design, and thereafter on the generation of novel ideas and solutions. It is remarkable that urban designers and students had dissimilar perceptions regarding the contribution of the different design factors to the creativity of the final design solution. The former considered that using design patterns for the 'analysis and evaluation of the design' had a negative contribution on most aspects of the design, and as a consequence, it limited the creativity of the final outcome. In contrast, the latter believe that this and the design innovation factor had a positive impact on their designs. However, irrespective of this, both students and urban designers agree that the use of patterns mainly aided in enhancing the functionality of the design, and to a lesser extent in improving its originality and aesthetic value.

Meaningful implications for design practice and design education can be derived from the result that, overall, the employment of urban patterns helps to enhance the functionality of the design. It is confirmed that these tools can be used to complement other approaches such as design heuristics and guidelines, providing more concrete aids. The solution examples that patterns afforded while dealing with specific urban problems showed to be helpful, suggesting that this tool can serve to overcome some of the weaknesses observed in these design methods. Their simplicity was very helpful to efficiently reduce the complexity of urban problems, as demanded in the design studio. A disadvantage, however, is that their well-structured knowledge and powerful descriptive power affected the ability to generate creative solutions to some extent. Specifically, patterns can be applied to structure the task in an effective way and to resolve urban situations mainly characterized by complex functional conflicts. They can also assist design teams, mainly heterogeneous ones, to develop a common language to enhance communication exchange and to create mutual understanding among team members.

The investigation also advances the present state of knowledge about the usage patterns in the urban design studio. That students demonstrated to be able to employ patterns to integrate and share their knowledge, also gives hope that this approach can be considered as a complement to more traditional education models, e.g., Ecole de Beaux Arts, which continue to be largely present in many schools of architecture and urbanism nowadays. Implementing educational programs in the urban design studio can grant avenues for genuine and efficient ways of using patterns. The approach offers 
an alternative to the long-established method characterized by transferring knowledge and skills from teachers to students. By teaching how to apply and adapt examples of successful schemas and solutions in practice, students will be able to enhance their skills, expertise, and body of knowledge in fast and efficient ways. As said before, there is some evidence of correspondence between the assessments made by urban designers and students regarding the assistance provided by the design patterns in the different aspects of the solutions. However, the greater divergence consisted in their perception on the contribution of the different factors to the final outcomes. Reducing divergences may enhance the chances of promoting learning in the urban design studio.

Limitations of this study, however, should be noted. The empirical research was carried out in a lab environment, which allowed for the isolation of study variables effectively. However, a disadvantage of using this method is that it differs in many ways from real-life design situations. Consequently, it is possible that the type of assignment given to the students might have influenced the way that they dealt with the task, and the limited repertoire of design patterns might also have impacted the produced outcomes. Another limitation is the low number of judges that evaluated the design outcomes. Although there was a high degree of agreement between the urban designers, using a larger group of judges in a future study would enable a better generalization of the current findings. In a similar vein, a larger number of participants could translate into a comparative study among students with different levels of expertise. Running a study on a yearly base would also enable to keep track of the role patterns in the development of knowledge and skills, and the ability to produce suitable solutions. This can contribute to a reflection on a broader picture of the significance and value of the design patterns at different levels of the urban studio. A future study can also employ more complex tasks, where the use of patterns by heterogeneous samples is explored, including multi-disciplinary teams composed by urbanists, architects, and environmental engineers.

Acknowledgments: This research was carried out in the Faculty of Architecture and the Built Environment, Delft University of Technology. The support provided by Arjan van Timmeren, and Petra Badke-Schaub is highly appreciated.

Conflicts of Interest: The authors declare no conflict of interest.

\section{Appendix A. Schipol's Airport Plaza}

The plaza located at the entrance of Schipol Airport is considered to be an awkward place and it is not used much today. You are requested to improve this place and convert it into a lively square.

For this aim, you are asked to propose different activities and design their related spaces in order to make the plaza a most enjoyable place for both travelers and residents of the area. Particular attention should be paid to the following aspects: generate small human scale places with defined borders/limits and with different levels of enclosure/privacy. Likewise, you should define the circulation layout and its relation to the different places in the square.

You are requested to generate as many creative ideas as possible, at a conceptual level of detail. You will be assigned a series of design patterns which you should use in your design since it was shown that they can help you to develop creative ideas.

Please number each sketch idea that you produce.

Good luck!

The research team

\section{References}

1. Akin, O.; Akin, C. On the process of creativity in puzzles, inventions, and designs. Autom. Constr. 1998, 7, 123-138. [CrossRef]

2. Goldschmidt, G.; Tatsa, D. How good are good ideas: Correlates of design creativity. Des. Stud. 2005, 26, 593-611. [CrossRef]

3. Karlgren, K.; Ramberg, R. The use of design patterns in overcoming misunderstandings in collaborative interaction design. CoDsign 2012, 8, 231-246. [CrossRef] 
4. Van Timmeren, A.; Delft University of Technology, Delft, The Netherlands. Personal communication, 2013.

5. Gerrits, L. A co-evolutionary revision of decision making processes: An analysis of port extensions in Germany, Belgium and The Netherlands. Public Adm. Q. 2011, 35, 309-339.

6. Pemberton, L. The Promise of Pattern Languages for Interaction Design. 2000. Available online: http: / /www.cmis.brighton.ac.uk/staff/lp22/HF2000.html (accessed on 1 September 2018).

7. Alexander, C. A Pattern Language; Oxford University Press: New York, NY, USA, 1977.

8. Alexander, C. The Timeless Way of Building; Oxford University Press: New York, NY, USA, 1979.

9. Simon, H. The structure of ill-structured problems. In Developments in Design Methodology; Cross, N., Ed.; John Wiley and Sons: New York, NY, USA, 1984; pp. 145-165.

10. Coplien, J.; Schmidt, D. Pattern Languages of Program Design; Addison-Wesley: Reading, MA, USA, 1995.

11. Dearden, A.; Finlay, J. Pattern languages in HCI: A critical review. Hum. Comput. Interact. 2006, 21, 49-102. [CrossRef]

12. Frauenberger, C.; Stockman, T. Auditory display design-An investigation of a design pattern approach. Int. J. Hum. Comput. Stud. 2009, 67, 907-922. [CrossRef]

13. Rodriguez, F.D.; Acuna, S.T.; Juristo, N. Design and programming patterns for implementing functionalities in web applications. J. Syst. Softw. 2015, 105, 107-124. [CrossRef]

14. Chung, E.S.; Hong, J.I.; Lin, J.; Prabker, M.K.; Landay, J.A.; Liu, A.L. Development and Evaluation of Emerging Design Patterns for Ubiquitous Computing. In Proceedings of the DIS'04 Conference, Boston, MA, USA, 1-4 August 2004.

15. Salingaros, N. The structure of pattern languages. Urban Res. Q. 2000, 4, 149-161. [CrossRef]

16. Duarte, J.P.; Beirão, J. Towards a methodology for flexible urban design: Designing with urban patterns and shape grammars. Environ. Plan. B Plan. Des. 2011, 38, 879-902. [CrossRef]

17. Atilola, O.; Tomko, M.; Linsey, J.S. The effects of representation on idea generation and design fixation: A study comparing sketches and function trees. Des. Stud. 2016, 42, 110-136. [CrossRef]

18. Jansson, D.; Smith, S. Design fixation. Des. Stud. 1991, 12, 3-11. [CrossRef]

19. Casakin, H.; Badke-Schaub, P. Sharedness of team mental models in the course of design-related interaction between architects and clients. Des. Sci. 2017, 3, 21. [CrossRef]

20. Badke-Schaub, P.; Buerschaper, C. Creativity and complex problem solving in the social context. In Decision Making: Social and Creative Dimensions; Allwood, C.M., Selart, M., Eds.; Kluwer: Dordrecht, The Netherlands, 2001; pp. 177-196.

21. Casakin, H.; Badke-Schaub, P. Mental models and creativity in engineering and architectural design teams. In Design Computing and Cognition'14; Gero, J.S., Hanna, S., Eds.; Springer International Publishing: Cham, Switzerland, 2015; pp. 155-171.

22. Badke-Schaub, P.; Neumann, A.; Lauche, K. An observation-based method for measuring the sharedness of mental models in teams. In Coordination in Human and Primate Groups; Boos, M., Kolbe, M., Kappeler, P.M., Ellwart, T., Eds.; Springer: Berlin, Germany, 2011; pp. 177-197.

23. Salingaros, N. Architecture, patterns, and mathematics. Nexus Netw J. 1999, 1, 75-85. [CrossRef]

24. Salingaros, N. Hierarchical cooperation in architecture, and the mathematical necessity of ornament. J. Urban Plan. Res. 2000, 17, 221-235.

25. Green, L.N.; Bonollo, E. Studio-based teaching: History and advantages in the teaching of design. World Trans. Eng. Technol. Educ. 2003, 2, 269-272.

26. Christensen, B.T.; Ball, L.J. Dimensions of creative evaluation: Distinct design and reasoning strategies for aesthetic, functional and originality judgments. Des. Stud. 2016, 45, 116-136. [CrossRef]

27. Maitland, B.M. Problem-based learning for architecture and construction management. In The Challenge of Problem-Based Learning; Boud, D., Feletti, G., Eds.; Kogan Page: London, UK, 1991; pp. 211-217.

28. Weisberg, R. Creativity, Beyond the Myth of Genius; W.H. Freeman and Co.: New York, NY, USA, 1993.

29. Amabile, T.M. Creativity in Context: Update to 'The Social Psychology of Creativity'; Westview Press: Boulder, CO, USA, 1996.

30. Sarkar, P.; Chakrabarti, A. Assessing design creativity. Des. Stud. 2011, 32, 348-383. [CrossRef]

31. Casakin, H.; Kreitler, S. Correspondences and divergences between teachers and students in the evaluation of design creativity in the design studio. Environ. Plan. B Plan. Des. 2008, 35, 666-678. [CrossRef]

32. Hanna, R.; Barber, T. An inquiry into computers in design: Attitudes before-attitudes after. Des. Stud. 2001, 22, 255-281. [CrossRef] 
33. Ward, A. Ideology, culture and the design studio. Des. Stud. 1990, 11, 10-16. [CrossRef]

34. Casakin, H.; Gigi, A. Cognitive styles in admission procedures for candidates of architecture. Assess. Eval. High. Educ. 2016, 41, 167-182. [CrossRef]

35. Cuff, D. Architecture: The Story of Practice; MIT Press: Cambridge, MA, USA, 1992.

36. Casakin, H.; Badke-Schaub, P. The psychology of creativity: Mental models in design teams. In Psychology of Creativity; Antonietti, A., Colombo, B., Memmert, D., Eds.; Nova Science Publishers: New York, NY, USA, 2013; pp. 167-180.

37. Casakin, H.; Kreitler, S. Correspondences and divergences in creativity evaluations between architects and students. Environ. Plan. B Plan. Des. 2008, 35, 666-678. [CrossRef]

38. Lee, N. Project methods as the vehicle for learning in undergraduate design education: A typology. Des. Stud. 2009, 30, 541-560. [CrossRef]

39. Griffiths, R.N.; Pemberton, L. Don't Write Guidelines Write Patterns! Available online: http:/ / www.cmis. brighton.ac.uk/staff/lp22/guidelinesdraft.html (accessed on 10 August 2018).

40. Arvola, M. Interaction design patterns for computers in sociable use. Int. J. Comput. Appl. Technol. 2006, 25, 128-139. [CrossRef]

41. Tavakol, M.; Dennick, R. Making sense of Cronbach's alpha. Int. J. Med. Educ. 2011, 2, 53-55. [CrossRef] [PubMed]

42. Casakin, H.; Kreitler, S. The nature of creativity in design: Factors for assessing individual creativity. In Proceedings of the Studying Designers International Conference, Aix-en-Provence, France, 17-18 October 2005.

43. Siang, J.K.K.; Koronnis, G.; Chia, P.Z.; Silva, A. Exploring the use of a full factorial design of experiment to study design briefs for creative ideation. In Proceedings of the ASME 2018 International Design Engineering Technical Conferences and Computers and Information in Engineering Conference (IDETC2018), Quebec City, QC, Canada, 26-29 August 2018.

44. Viera, A.J.; Joanne, M.D.; Garrett, M. Understanding inter-observer agreement: The kappa statistic. Fam. Med. 2005, 37, 360-363. [PubMed]

45. Thompson, B. Exploratory and Confirmatory Factor Analysis: Understanding Concepts and Applications; American Psychological Association: Washington, DC, USA, 2004.

46. Golberg, M.A.; Cho, H.A. Introduction to Regression Analysis; WIT Press: Billerica, MA, USA, 2004.

47. Fabrigar, L.R.; Wegener, D.T.; MacCallum, R.C.; Strahan, E.J. Evaluating the use of exploratory factor analysis in psychological research. Psychol. Methods 1999, 4, 272-299. [CrossRef]

48. Dorst, K.; Cross, N. Creativity in the design process: Co-evolution of problem-solution. Des. Stud. 2001, 22, 425-437. [CrossRef]

49. Stempfle, J.; Badke-Schaub, P. Thinking in design teams: An analysis of team communication. Des. Stud. 2002, 23, 473-496. [CrossRef]

50. Goldschmidt, G. Linkographic: Evidence for concurrent divergent and convergent thinking in creative design. Creat. Res. J. 2016, 28, 115-122. [CrossRef]

51. Casakin, H.; Ball, L.; Christensen, B.; Badke-Schaub, P. How do analogizing and mental simulation influence team dynamics in innovative product design? Aiedam 2015, 29, 173-183. [CrossRef]

52. Owen, W.F. Metaphor analysis of cohesiveness in small discussion groups. Small Group Res. 1985, 16, 415-424. [CrossRef]

53. Zangwill, N. Aesthetic Judgment. Stanford Encyclopedia of Philosophy. Available online: https://plato. stanford.edu/entries/aesthetic-judgment/ (accessed on 1 October 2018).

54. Kant, I. Critique of Judgement; Pluhar, W.S., Translator; Hackett Publishing Co.: Indianapolis, Indiana, 1987.

55. Riedel, T. Review of Encyclopedia of Aesthetics 4 vol. Michael Kelly. J. Art Libr. Soc. N. Am. 1999, 18, 48.

(C) 2018 by the author. Licensee MDPI, Basel, Switzerland. This article is an open access article distributed under the terms and conditions of the Creative Commons Attribution (CC BY) license (http://creativecommons.org/licenses/by/4.0/). 